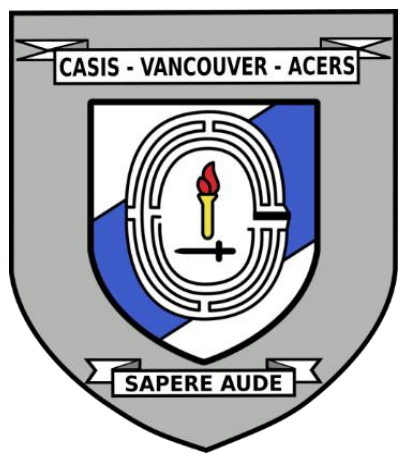

\title{
HOW SMALL STATES WORK TOGETHER FOR REGIONAL SECURITY IN COMPLEX SECURITY THREAT ENVIRONMENTS
}

Date: November 23, 2020

Disclaimer: This briefing note contains the encapsulation of views presented by the speaker and does not exclusively represent the views of the Canadian Association for Security and Intelligence Studies.

\section{KEY EVENTS}

On November 23, 2020, Major Kerry Waterman of the Regional Security System (RSS) presented at the 2020 CASIS West Coast Security Conference on the topic of, How Small States Work Together for Regional Security in Complex Security Threat Environments. The presentation was followed by a group panel for questions \& answers.

\section{NATURE OF DISCUSSION}

\section{Presentation}

Major Waterman outlined the history, mandate, and future goals of the RSS and how international collaboration, particularly between small states, is essential in maintaining security and countering contemporary threats as crime and security challenges have become increasingly transnational.

\section{Question Period}

During the question period, gender bias was discussed with regards to how it affects the issue of data analytics and what strategies can be taken to address it.

\section{BACKGROUND}

\section{Presentation}

National security is ultimately the responsibility of the state and, therefore, the governments are responsible to defend and secure their people. The RSS compliments such state security operations through cooperation, collaboration, 
and the sharing of resources. The RSS' mission is to ensure the stability and wellbeing of member states through mutual cooperation, with an ultimate goal of maximizing regional security and preserving the socioeconomic development of their citizens.

The RSS was established during the Cold War conflict and was one of the first state alliances in the Western Hemisphere. The RSS has evolved over the years to keep pace with the constantly changing security landscape by repeatedly reinventing itself and broadening its stakeholder networks in order to better protect security interests and values. By the 1990s, the RSS started taking a multidisciplinary approach, which expanded its functional responsibility with its seven-national alliance.

The structure of the RSS includes an executive director, who is assisted by a deputy executive director and headquarter staff. The deputy executive director is responsible for four directors: the director of training, the director of asset recovery, the director of operations and plans, and the director of policing and risk management. Together, the members of the RSS monitor and address threats to nation-states in two tiers. Tier one includes transnational organized crime, gangs, organized crime, cybercrime, financial crimes, and corruption. The second tier focuses on human trafficking, smuggling, national disasters, and public disorder crimes.

The asset recovery unit provides regional support to combat money laundering and organized crime to take the profit out of crime. They also support financial intelligence units, law enforcement and criminal justice practitioners within their member states. To date, 2.3 million US dollars have been recovered by this unit.

In terms of achievements, the RSS' air wing has had success in their counterdrug missions with 834 arrests, nearly 800 prosecutions, and seizure of 128,000 lbs of marijuana and 21,000 kilos of cocaine. In addition, the RSS has seized 195 vessels, 29 firearms, and nearly three million US dollars. Their goal is to develop their air wing into a centre of excellence by the year 2035, with improved drone capabilities, advanced submersible detection, and greater capability of all operational types. The RSS would also like to improve their infrastructure and develop their multipurpose digitized operation centre in order to provide enhanced service to their partners and select private entities.

In particular, the digital forensics lab has been making exciting advancements as it is responsible for investigating the contents of various devices to support 
robbery, drug possession, murder, kidnapping and cybercrime investigations, among others. The RSS has been working with the US government to develop their capabilities and have gained support from the international law enforcement anti-crime mission to develop their forensic labs. An upcoming project of the RSS is to construct an index data repository to streamline the classification process within the forensic labs, as well as to maintain international law enforcement standards.

One of the most important aspects of the RSS is its training institute whose vision is to build a standardized training program to enable the continuous development of the security sector through learning, while maintaining professional standards and conduct. In their three-year training plan, the RSS is looking at improving the way they do business by focusing on curriculum development, ongoing monitoring and evaluation of training delivery, and ensuring certifications are current. They plan to improve their digitization of training materials to facilitate awareness and accessibility to their member states as well.

The RSS faces several challenges, most notably funding limitations and inadequate patrol capabilities. Currently, their strategic air and sea patrols are limited as there is no coastal radar coverage in Northern member states and in some instances, there is a lack of national security policies. By strengthening their institutional capacity within the RSS and building partnerships external to the RSS, they will be able to better serve the sub-region and a wider international community by reducing the number of threats.

The RSS has developed seven maritime strategies and one regional overarching strategy to address these challenges and to assist member states to bring about an integrated strategic approach to security in their maritime domain. The three expected outputs from this project include the implementation of standardized aggregated crime data reporting, the utilization of evidence-based analysis on crime data and improved decision-making capabilities with regard to youth crime and violence.

\section{Question Period}

Gender bias and cultural bias can affect the issue of data analytics, but it is important to take a step back and be objective. We must analyze the data in front of us without allowing those cultural biases to influence the way we interpret the data. The best way to achieve objectivity is to ensure that individuals are well trained to check their biases. It takes a generation to change a culture, so by 
incorporating training into policing academies and other law enforcement agencies now, those individuals can learn and pass on their knowledge and training to the next generation down the line.

\section{KEY POINTS OF DISCUSSION}

\section{Presentation}

- The RSS compliments state security operations through cooperation, collaboration, and the sharing of resources, with an ultimate goal of maximizing regional security and preserving the socioeconomic development of their citizens.

- The RSS has a number of achievements, primarily in counter-trafficking efforts; however, they also face several challenges, most notably funding and inadequate patrol capabilities.

- The RSS has developed seven maritime strategies and one regional strategy to address these challenges and to assist the member states to bring about an integrated strategic approach to security in their maritime domain.

- Their goal is to develop their air wing into a centre of excellence by the year 2035, with improved drone capabilities, advanced submersible detection and greater capability of all operational types.

- The RSS is also looking to the future to innovate, train, and better ensure safety for their partner states and the greater Caribbean region.

\section{Question Period}

- Gender and cultural bias can affect the issue of data analytics; therefore, it is important to analyze data without allowing cultural biases to influence how the data is interpreted.

- The best way to achieve objectivity is to incorporate training into police academies and law enforcement agencies, so that the trained individuals can pass on their knowledge to the next generations.

The Journal of Intelligence, Conflict, and Warfare 


\section{(c) (i) ()}

EY No ND This work is licensed under a Creative Commons AttributionNon-Commercial-No-Derivatives 4.0 International License.

(C) (KERRY WATERMAN, 2021)

Published by the Journal of Intelligence, Conflict, and Warfare and Simon Fraser University

Available from: https://jicw.org/ 